\title{
Continuing medical education: experience and opinions of consultants
}

\author{
David N S Kerr, S Angela M Jones, Charles S F Easmon
}

\begin{abstract}
The right of consultants to study leave and expenses is not binding on trusts and has been eroded in directly managed units. Complaints led to a survey of consultants in North West Thames region. This showed that most consultants use their own time and money to maintain their knowledge by buying and consulting journals and textbooks, attending local meetings, and using their annual leave for study, but they feel the need for study leave to attend meetings of specialist societies and courses. Leave is usually granted readily but without cover provided by a locum and with a very limited contribution to expenses. To maintain quality of medical care both the right and obligation to take study leave should be contractual.
\end{abstract}

A physician who qualified in the 1920 s said as he retired, "When I was a house physician I had only half a dozen effective drugs at my disposal, now I have several hundred. Nothing in my medical training prepared me for this explosion of clinical pharmacology." Consultants retiring in 1992 look back on many more dramatic developments during their graduate careers most of which they were unprepared for. They range from scientific milestones such as the cracking of the genetic code, the birth of molecular biology and modern genetics, the discovery of the HLA system, and the start of organ and tissue transplantation to everyday medicine such as coronary care and thrombolysis, coronary angiography, angioplasty, and bypass surgery, to mention only a few.

Self evidently, medical and scientific education must continue unabated throughout a consultant's life. This was recognised in 1971 in the conditions of service of consultants set out in a document often referred to as the "red book." A retrospective analysis of study leave in 1990 by the Standing Committee on Postgraduate Medicine showed that consultants took less than their allowance-an average of $6 \cdot 2$ days a year. ${ }^{2}$ During 1991 the public health directorate of North West Thames Regional Health Authority received complaints from several consultants about further erosion of these provisions after the responsibility for continuing medical education was devolved to units and trusts in April 1991. The authority had distributed its budget for continuing medical education to district health authorities before the April 1991 deadline. The complaints arose during the period after the transfer, when it was widely believed that the budget had not always been used for its intended purpose. ${ }^{3}$

We conducted an initial survey by telephone which showed that this was not just the view of a disgruntled few. We therefore conducted a wider survey of the experience and opinions of consultants. A questionnaire was sent to a 1 in 5 sample of the 1338 consultants in the region. These included honorary contract holders, mainly university staff in St Mary's and Charing Cross and Westminster Hospital Medical Schools, who carry out a substantial amount of the consultant work in inner London.

\section{Methods}

The sample was drawn from the regional file of consultant staff. Each consultant has a number; from these a 1 in 5 sample was chosen by using random numbers. No stratification was used.

The questionnaire was designed in house and tested on members of staff in the directorate and, in its penultimate form, on regional advisers, who were asked to criticise it. The final version sought factual information about the consultant's use of study leave over the past two years (one year in the case of three consultants between one and two years in post); the local arrangements for obtaining study leave and expenses and any ceiling on reimbursement; and their future intended use of study leave. Consultants were asked to give their view of the main purposes of study leave before being cued by direct questions; to list the other methods they used to keep up to date; to rank the value of these methods to them personally; and to rank the importance of arguments in favour of retaining and protecting study leave. Copies of the questionnaire are available on request from the authors.

\section{Results}

THE RESPONSE

To the 268 questionnaires distributed a reply was received from 135 after the initial inquiry and from 204 after two reminders. The 64 non-responders included 29 for whom reasons were provided (one had died, three had retired, six had moved, one was on sabbatical, three were on long sick leave, three were recently appointed, six were about to retire, five were holders of contracts inapplicable to questionnaire, and one was "too busy to take study leave for past 12 years"). The response rate from those who were eligible to respond was therefore $85 \%$.

The combined effect of sampling error and differential rates of return between specialties resulted in an overrepresentation of psychiatric disciplines $(23 \%$ against an expected $13 \%$ in the region) balanced by a modest underrepresentation of medical (24\% against an expected $29 \%$ ) and other disciplines, but the replies were drawn from 47 medical and dental specialties and from all the district general and teaching hospitals in the region. Fourteen $(7 \%)$ of the respondents were university staff, among whom those who took a large amount of study leave were overrepresented (see below). No conclusion of the survey, however, is altered by omitting the academic group so we report NHS and university staff together. Responses from two consultants who were in post for less than one year and two with unusual contracts were used for the questions on opinions but omitted from some or all of the factual ones.

USE OF STUDY LEAVE

Sixteen of the respondents had taken no study leave in the past two years; $112(56 \%)$ had taken half or fewer of the 10 days recommended in the guidelines of the red book (figure). Of the 31 who had taken more than 10 days, 10 were academic staff working to university regulations and one was an NHS consultant who had been granted a two month sabbatical. As the provisions in the red book are averaged over a three year period, leave in a two year period may legitimately exceed the allowance by up to $50 \%$. Those NHS consultants whose use was greater than this were presumably
Correspondence to:

BMF 1993;306:1398-402 
benefiting under paragraphs 252 and 253 of the red book (box).

\section{EASE OF OBTAINING STUDY LEAVE}

Most consultants (183/195 (94\%)) said that they had not been refused a request for study leave in the past two years. Of those who had been granted study leave, $83 \%(138 / 160)$ judged that it had been granted readily rather than grudgingly. Criticism was directed almost entirely at the bureaucracy and particularly at the difficulty of obtaining funds to defray their expenses.

\section{USE OF STATUTORY LEAVE FOR STUDY}

Ninety five consultants $(48 \%$ of those who answered this question) had used part of their statutory leave for study that was suitable for study leave. The average time used was 7.5 days with a range of one to 42 days over two years, and $90(95 \%)$ had paid their own expenses in part or full. Because of this use of statutory leave and, in some cases, of study leave taken without approval the time recorded for the activities listed below exceeded their official study leave.

\section{USES OF STUDY LEAVE}

Table I shows the uses to which study leave was put,

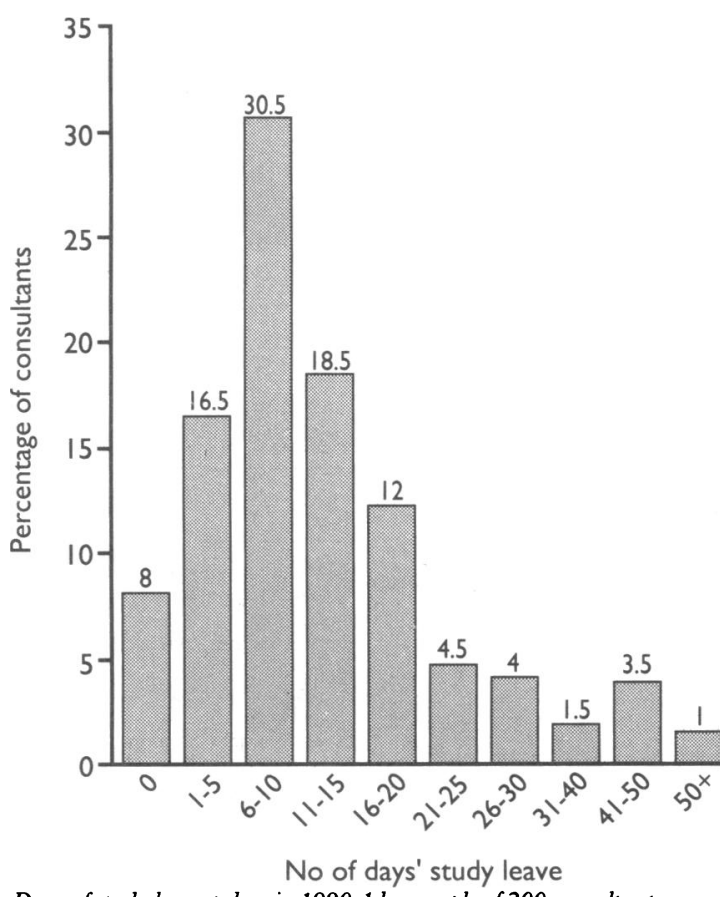

Days of study leave taken in 1990-1 by sample of 200 consultants

TABLE I-Uses to which study leave and statutory leave taken for study were put in 1990-1 among 200 consultants

\begin{tabular}{|c|c|c|c|c|}
\hline \multirow[b]{2}{*}{ Purpose } & \multirow[b]{2}{*}{ No of consultants } & \multicolumn{3}{|c|}{ No of days used } \\
\hline & & $\begin{array}{l}\text { Mean per consultant } \\
\text { taking leave for this } \\
\text { purpose }\end{array}$ & $\begin{array}{l}\text { Mean for all } \\
\text { consultants }\end{array}$ & Range \\
\hline \multicolumn{5}{|l|}{$\begin{array}{l}\text { Attending conferences } \\
\text { of specialty societies: }\end{array}$} \\
\hline National & 172 & $6 \cdot 7$ & $5 \cdot 6$ & $1-24$ \\
\hline European & 57 & $5 \cdot 4$ & 1.5 & $1-15$ \\
\hline American & 39 & $6 \cdot 7$ & $1 \cdot 3$ & $2-15$ \\
\hline International & 32 & $7 \cdot 1$ & $1 \cdot 2$ & $1-23$ \\
\hline \multicolumn{5}{|c|}{ Attending meetings } \\
\hline Within United Kingdom & 45 & $2 \cdot 4$ & 0.5 & $1-12$ \\
\hline Abroad & 27 & $4 \cdot 2$ & 0.6 & $1-14$ \\
\hline \multicolumn{5}{|l|}{ Attending other meetings: } \\
\hline Within United Kingdom & 49 & $6 \cdot 2$ & 1.4 & $1-34$ \\
\hline Abroad & 12 & $9 \cdot 2$ & 0.5 & $1-23$ \\
\hline \multicolumn{5}{|l|}{ Guest lecturing: } \\
\hline Within United Kingdom & 33 & $7 \cdot 7$ & $1 \cdot 2$ & $1-21$ \\
\hline Abroad & 33 & $5 \cdot 7$ & $1 \cdot 1$ & $1-21$ \\
\hline Attending courses & 69 & $5 \cdot 1$ & $1 \cdot 7$ & $1-50$ \\
\hline Visiting other centres & 41 & $5 \cdot 4$ & $1 \cdot 1$ & $1-60$ \\
\hline to learn new techniques & & $4 \cdot 0^{\star}$ & $0 \cdot 8^{\star}$ & $1-14^{\star}$ \\
\hline
\end{tabular}

$\star$ Omit one 60 day visit.

\section{Provisions for consultant study leave in the "red book"1}

- 250 Professional or study leave is granted for postgraduate purposes approved by the employing authority and includes study ... research, teaching, examining or taking examinations, visiting clinics and attending professional conferences

- 251 Professional or study leave will normally be granted to the maximum extent consistent with maintaining essential services.... The recommended standard (is) leave with pay and expenses, within a maximum of thirty days (including off duty days falling within periods of leave) in any period of three years for professional purposes within the United Kingdom

- 252 Authorities may at their discretion grant professional or study leave in the United Kingdom above the periods recommended in paragraph 251 with or without pay and with or without expenses or with some proportion thereof

- 253 Authorities may at their discretion grant professional or study leave outside the United Kingdom with or without pay and with or without expenses or with any proportion thereof

the proportion of consultants using it for these purposes, and the average time taken over two years.

\section{FUTURE PLANS FOR STUDY LEAVE}

The question was asked, "If study leave within (red book) regulations remains freely available and funded within a reasonable budget, do you plan to alter your use of it?" Table II summarises the replies. The results show a strong desire among many consultants to spend more time in continuing medical education if it is made reasonably easy but give no guide to how much will be achieved if the present constraints on taking study leave remain or increase.

TABLE II-Plans for future study leave among 204 consultants if conditions in "red book" are maintained

\begin{tabular}{lcc}
\hline & \multicolumn{2}{c}{$\begin{array}{c}\text { No of consultants planning to } \\
\text { change this use of leave }\end{array}$} \\
\cline { 2 - 3 } Purpose of leave & Expand & Contract \\
\hline Attending meetings & 82 & 0 \\
Attending courses & 77 & 5 \\
Lecturing & 32 & 2 \\
Visiting other centres & 63 & 3 \\
\hline
\end{tabular}

REIMBURSEMENT FOR STUDY LEAVE

Our initial telephone inquiry showed widespread ignorance of how study leave and expenses should be requested under the recently changed procedures. We were warned by regional advisers that if we asked consultants to describe the arrangements in their hospitals the effort required to find the answer would deter most of them from filling in the questionnaire. We were, however, anxious to ask this question, which was at the heart of the complaints we had received, so we retained it in the questionnaire. We tried to discover the new pathways in each hospital by inquiries to the chief executives' offices or the medical directors and chairs of medical staff committees. We received replies to half these requests and sent a summary of them with the questionnaire to those working in the hospitals concerned. Despite this help 49 replies merely confirmed ignorance of who now held the budget for study leave. Of the 155 who answered the question, with or without our help, 60 believed that it was the chief executive, directly or through the personnel officer or director of human resources; 25 the clinical director; 32 the unit director (from a devolved budget); and 38 others including the clinical tutor, 
chair (or ex-chair) of the medical staff committee, and half a dozen other designated people.

Of the 173 who expressed an opinion, 28 believed that the study leave budget was sufficient to meet all requests, though several commented that this was only because few consultants applied; 62 said there was an arbitrary limit on the amount that each consultant could receive in one year, which in $80 \%$ of cases was between $£ 100$ and $£ 300$; 81 said that the total budget was severely restricted. In one of the largest hospitals the budgets for postgraduate and continuing medical education had been combined and the whole sum was now devoted to junior staff so there was none available for consultants.

Sixty consultants $(30 \%)$ had access to alternative funds such as fees from private patients seen for institutional gain, and 21 had potential access to directorate funds which could be redirected from other purposes.

\section{OTHER METHODS OF KEEPING UP TO DATE}

fournals-Nearly all consultants $(200 ; 98 \%)$ took journals personally by subscription or through membership of societies. The average number taken was 4.0 with a range of one to 16 . One hundred and fifty nine consulted journals regularly in a library; the mean (range) number was 3.9 (1-25).

Textbooks-One hundred and seventy five had bought a major textbook within the past five years. There were 10 bookworms who had bought between 30 and 100 textbooks over five years. The mean number for the remainder was $5 \cdot 2$. This study focused on journals and books bought personally because we believe that these are the ones that are read most assiduously. Several respondents, however, referred to the common practice of buying textbooks for departmental libraries from "slush funds" and then reading them at home as an additional form of study.

Video and audio cassettes-Only 43 consultants made regular use of these.

Local evening and weekend meetings such as local medical societies-Sixteen consultants attended such meetings at least weekly, 51 at least monthly, and 96 less frequently.

\section{RELATIVE IMPORTANCE OF DIFFERENT FORMS OF} CONTINUING MEDICAL EDUCATION

Consultants were asked to rank in importance to them personally any of the preceding methods of keeping up to date against attending conferences, courses, or other departments during study leave; regular meetings in hospital such as $x$ ray and pathology conferences; activities in the postgraduate centre during the working day; and visits from representatives of pharmaceutical companies. Table III shows the results. Their relative importance is shown by the number of consultants who used them and by the order in which they rated them, which was expressed as a popularity score-the mean of the ratings subtracted

TABLE III-Relative importance to 204 consultants of various methods of keeping up to date

\begin{tabular}{lcc}
\hline Method & $\begin{array}{c}\text { No of consultants rating } \\
\text { it important to them }\end{array}$ & $\begin{array}{c}\text { Popularity } \\
\text { score }^{\star}\end{array}$ \\
\hline Conferences or meetings in study & & \\
leave & 190 & $6 \cdot 9$ \\
Courses in study leave & 149 & $6 \cdot 0$ \\
Visiting other centres in study leave & 120 & $4 \cdot 2$ \\
Routine meetings in hospital & 171 & $5 \cdot 6$ \\
Local evening or weekend meetings & 112 & 3.9 \\
Reading journals & 195 & $6 \cdot 7$ \\
Reading textbooks & 168 & $4 \cdot 5$ \\
Video and audio cassettes & 84 & $2 \cdot 2$ \\
Visits from representatives of & 86 & $2 \cdot 0$ \\
$\quad$ pharmaceutical firms & 86 & \\
\hline
\end{tabular}

*Calculated as 9 minus mean of priority ratings awarded by those who used it. Top possible score is 8 , lowest possible 0 . from the number of choices; a high score indicates popularity.

\section{DIRECT CONTACT WITH COLLEAGUES}

At three points in the questionnaire free comment was invited on methods of keeping up to date. There was very frequent reference to talking to colleagues locally, regionally, or nationally directly or by telephone and to informal meetings with colleagues at conferences. Some replies spelt out the benefits: learning from colleagues in different specialities during discussion of patients; sharing concerns about clinical problems and organisational changes; and getting to know the experts on various topics in your own specialty so that you know where to turn when in difficulty. This is known in public health circles as "networking" and is clearly rated very highly by many consultants, though it was not quantified in this study. One respondent rated this as such an important part of continuing medical education that he considered the one hour a week he spent on the telephone discussing management of patients with colleagues should be part of contracted time.

\section{ARGUMENTS FOR PROTECTING STUDY LEAVE}

As the survival of paid study leave to improve clinical, teaching, and research skills seemed to be under threat we asked consultants to rank in importance any of five arguments for it, which had been identified in our initial telephone survey, that were applicable to them. As in the previous section we have expressed their importance in terms of the number of consultants who supported them and in a popularity score based on their ratings (table IV). The importance attached to personal contacts with colleagues is again emphasised.

TABLE IV-Relative importance attached to five possible reasons for protecting study leave by 204 consultants

\begin{tabular}{lcc}
\hline Reason & $\begin{array}{c}\text { No of consultants rating } \\
\text { it as important }\end{array}$ & $\begin{array}{c}\text { Popularity } \\
\text { score }^{\star}\end{array}$ \\
\hline $\begin{array}{l}\text { Allows acquisition of new skills } \\
\text { which require hands on } \\
\text { experience }\end{array}$ & 157 & 3.0 \\
$\begin{array}{l}\text { Permits escape from pressure of } \\
\text { work }\end{array}$ & 124 & 2.0 \\
$\begin{array}{l}\text { Essential to meet colleagues in your } \\
\text { specialty }\end{array}$ & 192 & 3.4 \\
$\begin{array}{l}\text { Keeps research of your unit in public } \\
\text { eye }\end{array}$ & 111 & 2.1 \\
$\begin{array}{l}\text { Lecturing by invitation brings } \\
\text { benefits to institution (for } \\
\text { example, recruitment of patients } \\
\text { and junior or research staff) }\end{array}$ & 115 & \\
\hline
\end{tabular}

^Calculated as 5 minus mean of priority ratings; maximum possible score 4 , minimum 0 .

\section{Discussion}

This study was conducted during a period of turmoil after devolution of budgets for continuing medical education to health authorities and trusts. It was also a time of very rapid change in many other aspect sof NHS medicine, particularly in and around London. Not surprisingly, therefore, there was widespread confusion among consultants about how to apply for study leave and the chances of obtaining financial support. Our retrospective survey of the use of study leave in the preceding two years was largely unaffected as most of this was requested before the changes. Clearly the procedures should be better publicised and well understood in every provider unit.

Only $35 \%$ of consultants had any idea whether their study leave budget was a protected sum and nearly half of these believed that it was not. Working for Patients

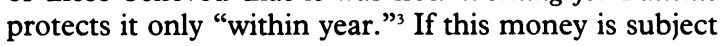
to erosion when times are hard it is certain to disappear 
quickly and completely in London, as has already happened in one major hospital. Should we make strenuous efforts to preserve it? Our survey suggests that the answer is emphatically yes. Consultants attach great importance to attendance at meetings of their specialist societies and rank this alongside journal reading as their main method of keeping up to date. There were many free comments on the importance of hearing new work presented or reviewed by the top experts in the subject. Some said that they gained much more from hearing presentations than reading but, to our surprise, no one mentioned the greater attention paid to journal articles when the author is known to the reader. Study leave to attend courses was also popular.

In general the preferences which consultants expressed (in tables III and IV) reflected their own use of study leave and of forms of continuing medical education. There is, however, a discrepancy between the number who attached importance to acquiring new skills by hands on experience or direct observation (see table IV) and the much smaller number who had taken leave for this purpose in the past two years. Presumably the need for this type of study arises at longer intervals than two years.

\section{PERSONAL EFFORT}

Consultants spend a creditable amount of their own time and money on continuing self education. Persuing the average four journals bought and four consulted in the library must entail several hours of reading and browsing each week. Purchasing the average four journals and one major textbook each year costs several hundred pounds. Paying for the average four days of statutory leave to attend medical meetings must cost the $45 \%$ of consultants who do this a further substantial sum. A third of consultants also sacrifice their evenings and weekends to attend local meetings on a regular basis.

One of the main disincentives to taking study leave, mentioned by many of our respondents, is the build up of work which must be dealt with on return. Only 40 of the 148 consultants who answered the question thought that funds were available for locums during study leave, and this was sometimes confined to single handed consultants, and only 80 believed that locums were available even if the money were forthcoming.

\section{ACCOUNTABILITY}

This evidence of personal effort and sacrifice by consultants is a valuable counter to the opinion sometimes expressed that study leave is a paid holiday. None the less, it must be acknowledged that the salaries of consultants while on study leave and their expenses are charges on public funds. They should be accountable for the effective use of these if the time and funds are to be protected in the future. This principle has been spelt out in Working for Patients:

High standards of ... continuing medical education are fundamental to the provision of high quality patient care in the NHS; the system for the delivery of ... continuing education should be part of the managerial structure with defined objectives, proper lines of accountability and budget holders responsible for allocation of funds and educational outcomes; the NHS retains the main responsibility for funding while the responsibility for maintenance of standards is vested in the Royal Colleges ... Universities and the General Medical and Dental Councils. ${ }^{3}$

The royal colleges are taking their role in setting standards seriously. They are preparing recommendations for a more formal plan of continuing medical education for consultants. The Royal College of Obstetricians and Gynaecologists has gone further and proposed a system of regular recertification by accumulation of cognate points-that is, credits for attendance at meetings and courses including local audit meetings, preparation for lectures and publications, and supervised acquisition of new techniques. ${ }^{4}$ It does not propose any credit for self learning aimed solely at self improvement, which our survey shows is one of the mainstays of continuing medical education. The Royal College of Physicians of Edinburgh has recommended regular (three to five year) inspections of continuing medical education with the ultimate sanctions of disqualifing a unit from training junior staff or withdrawing specialist registration.

We shall soon have such guidance for all major branches of hospital medicine. We now need the NHS organisation to match it. Working for Patients states that "the funding for study leave and associated costs for hospital career grades will be held in a protected budget at unit level. Clinical tutors in consultation with local professional interests and in the case of dentists with the regional postgraduate dental deans will be responsible for identifying in agreement with unit managers the appropriate level of funding and monitoring its use." ${ }^{3}$ This sounds like a prescription for endless wrangling with no final arbiter.

In our view it is a mistake to separate postgraduate medical education from continuing medical education. It supports the erroneous belief that postgraduate medical education is essential and continuing medical education an extra; education should continue without pause from graduation to retirement. We hope that the Department of Health will think again and involve the postgraduate dean in the whole process as recommended by the Standing Committee on Postgraduate Medical Education. ${ }^{6}$ In the meantime we suggest that continuing medical education should be built into consultant contracts as both a right and an obligation.

\section{RIGHT TO STUDY LEAVE}

Consultants already have the right to buy as many journals and textbooks as they wish; by a quirk of our quaint system of taxation the cost is not allowable against salary though it is allowable against schedule $\mathrm{D}$ earnings from private practice, writing, and examining, an anomaly that should be rectified. Study leave requires the sanction and financial support of the employer. The provisions in the red book (see box) are still in force in directly managed units and could be used as a national yardstick against which to measure the arrangement negotiated in trusts. That they are not overgenerous in time is shown by the fact that many consultants make up in privately taken and funded leave the shortfall in official study leave.

\section{OBLIGATION TO CONTINUE EDUCATION}

The clinical staff of universities undergo a regular (usually annual) appraisal. Senior lecturers, readers, and professors discuss with their appraiser their achievements in clinical or laboratory practice, teaching, and research, their needs for career development, and their plans to achieve it. There is no NHS equivalent. If the current review of medical training in the light of European Community regulations results in a specialist grade being interposed between training and consultant grades ${ }^{7}$ it is easy to foresee a university style appraisal in a more hierarchical NHS. The possible form of an appraisal system for the existing structure is under active discussion within the Standing Committee on Postgraduate Medical Education. For the moment clinical tutors, whose role in continuing medical education has been enhanced by Working for Patients, ${ }^{3}$ seem the obvious people to arrange at least the scrutiny of requests for continuing medical education and the audit of their benefit. They could be helped in this task by local postgraduate education committees, which they chair. Consultants would 
present a plan for continuing medical education for the next year and approval should ensure the granting of study leave and expenses within the plan, subject only to satisfactory arrangements for the service.

\section{EDUCATIONAL AUDIT}

Increasing attention is now paid to the audit of undergraduate and academic postgraduate education. ${ }^{8}$ Vocational postgraduate medical education is coming under similar and long overdue scrutiny. ${ }^{9}$ Continuing medical education will be the most difficult to audit. We have no established methods for measuring the quality of work done by consultants which could be used to judge whether continuing medical education affected it; recertification by examination is used voluntarily in the United States and the possibility of compulsory periodic re-examination is being discussed. The reproducibility of examinations such as memberships, fellowships, and exit examinations for specialists would have to be established before they could even be considered as periodic checks on knowledge and skills. Measuring the process is a poor substitute for measuring the output but one that has to be accepted in many aspects of clinical audit and will have to suffice in judging continuing medical education until we have proved measures of output. We strongly urge the setting up of a system of audit which is simple to operate and has a single, clearly defined line of accountability.

$\cos \mathrm{T}$

The cost of funding 10 days of study leave a year in the United Kingdom with course fees and travel expenses paid (in accordance with red book guidelines) would exceed $£ 1000$ per consultant per year, five times the modal financial ceiling of $£ 200$ per year imposed by units in North West Thames region. If all consultants presented a well thought out plan for their continuing medical education and had to defend it and the meetings and courses selected to their appraisers or a continuing medical education committee, however, the cost could well be more modest and the trust board or health authority would enjoy proper accountability in return for a simplified system and a guaranteed level of reimbursement. They would also have the reassurance that their staff were keeping their skills and knowledge well honed; continuing medical education is primarily for the benefit of patients but it should also reduce the bill to employers for medical negligence.

\section{RESEARCH AND DEVELOPMENT}

Surveys of what consultants have found by trial and error helps to maintain and develop their skills is not an ideal foundation on which to build the future of continuing medical education but it is the only one we have. Controlled trials have shown that some aspects of performance, such as the use of laboratory tests and drugs, can be improved by specific training, but proof that overall clinical performance can be improved is less impressive. ${ }^{10}$ Meaningful research on the effectiveness of continuing medical education in hospital medicine in this country is almost nonexistent. Developing reliable measures of performance which could be used to judge the effect of continuing medical education should be one of the priorities in research and development within the NHS.

We thank Dr Sheila Adam, director of public health; Dr Elizabeth Shore, postgraduate dean; and the regional advisers of North West Thames Regional Health Authority for help and advice in the design of the survey and questionnaire, and Julian Cooke and Michael Keane for help with the random selection and analysis. We are particularly grateful to consultant colleagues who gave the time and effort to complete yet another questionnaire.

1 Department of Health. Hospital medical and dental staff (England and Wales). Terms and conditions of service. London: Department of Health, 1986.

2 Standing Committee on Postgraduate Medical Education. Uptake and costs of study leave. London: SCOPME, 1991.

3 NHS Management Executive. Working for patients. Postgraduate and continuing medical education. Lancashire: Health Publications Unit, 1991. (Originally medical education. Lancashire: Health Publications Unit, 1991

published as Education and training. Working paper 10,1990.)
4 Royal College of Obstetricians and Gynaecologists Working Party. Report on Royal College of Obstetricians and Gynaecologists Working Party. Report on
continuing medical education. London: Royal College of Obstetricians and

5 Royal College of Physicians of Edinburgh. Continuing medical education for trained physicians. Edinburgh: Royal College of Physicians of Edinburgh 1992.

6 Standing Committee on Postgraduate Medical Education. Third report. London: SCOPME, 1992

7 Calman KC. Specialist medical training in the UK. London: Department of Health, 1992. (PLCMO(92) 13.)

8 CVCP Academic Audit Unit. Annual report of director 1990-91. Birmingham Higher Education Quality Council, Division of Quality Audit, 1991.

9 Grant J, Chambers E, Hodgson B, Kirkwood A, Morgan A, Macdonald M. A study of formal opportunities in postgraduate education for hospital doctors. London: SCOPME, 1992.

10 Davis DA, Thomson MA, Oxman AD, Haynes RB. Evidence for the effectiveness of CME. A review of 50 randomised controlled trals. $\varsubsetneqq A M A$ 1992;268:1111-7.

(Accepted 4 March 1993)

\section{A DEATH THAT DETERMINED MY CAREER}

\section{Unfair and unnecessary}

I was doing a general practice locum in Stockport and the housemaid called me at about 4 o'clock in the morning for an emergency. It was "a baby case," so I pulled a suit over my pyjamas, picked up the maternity case, and left with the boy who had brought the message. The house was a tenement in a slum, and the open front door led directly into the main room. I was greeted by a slatternly midwife, who said: "I'm afraid you're too late, doctor." The patient was lying on a large iron bedstead which occupied most of the room. Her face was startlingly white, the pallor accentuated by her black hair, and she was obviously dead. She was covered by a bloodstained blanket. "It was a postpartum 'emorrhage," said the nurse.

I felt for a wrist, jugular, or apical beat and gave an intracardiac injection of adrenalin, followed by chest massage, with no result. Then I looked at the baby, lying wide eyed on an older woman's lap, soundless but apparently quite healthy. The woman was methodically cleaning him. She looked up at me and said: "I'm her mother. I'll take him." I asked the patient's name. "Jenny Jones, 28 last birthday," she said.

I got the history from the nurse. A three day labour; a botched attempt to express an unseparated placenta; a torrential blood loss. I stared at the dead face and said, "What a pity." The nurse took this as a rebuke and said loudly, "It wasn't my fault." I had mixed thoughts on that but said nothing and put my things away in the bag. On my way out the grandmother looked up and said, "I'll send the boy for the certificate in the morning, doctor." She was evidently accustomed to bereavement.

The case affected me profoundly. I was used to the legitimate deaths of war, road accidents, and illness, but this was so gratuitously unfair. This young woman had died while carrying out a natural physiological function. And her death, the result of incompetent midwifery carried out in quite inadequate surroundings, had been totally unnecessary.

I had not yet decided about my professional future. This case made the decision for me and I started my first obstetric post two weeks later. I have never regretted it. I can think of no specialty of such engrossing human and technical interest or one giving such clinical satisfaction in its practice.-ALBERT DAVIS is a retired obstetrician in London 